\title{
Mechanical Behaviour of ETICS in Presence of Water
}

\author{
Fulvio Re Cecconi ${ }^{1}$, Giuseppe Cocchetti ${ }^{2}$, Aram Cornaggia ${ }^{3}$ and Tomaso Villa \\ 1 \\ Architecture, Built environment and Construction engineering - ABC Department, Politecnico di \\ Milano, via Ponzio 31, 20133-Milano, Italy, fulvio.rececconi@polimi.it \\ ${ }^{2}$ Civil and Environmental engineering - DICA Department, Politecnico di Milano, piazza Leonardo \\ da Vinci 32, 20133-Milano, Italy, giuseppe.cocchetti@polimi.it \\ ${ }^{3}$ Civil and Environmental engineering - DICA Department, Politecnico di Milano, piazza Leonardo \\ da Vinci 32, 20133-Milano, Italy, aram.cornaggia@polimi.it \\ ${ }^{4}$ Chemistry, Materials and Chemical Engineering "Giulio Natta" - DCMIC Department, Politecnico \\ di Milano, piazza Leonardo da Vinci 32,20133-Milano, Italy, tomaso.villa@polimi.it
}

\begin{abstract}
Climate change and the request for better assets' energy performances are forcing the construction sector towards passive or even active buildings: assets with a positive balance between energy production and consumption. Building insulations play a crucial role in reducing energy demand. One of the most used technology to insulate new and refurbished buildings are the External Thermal Insulation Composite Systems (ETICS). Despite their thermal advantages, low cost, and ease of application, these systems may have serious problems if not well designed. Cracks on the coating layer are among the most common pathologies during ETICS service life. They have been studied using a Finite Element Method (FEM) analysis on two different types of ETICS in order to understand how cracks and the mechanical characteristics of materials used in the ETICS are related. The results show that errors during ETICS installation impacts on cracks occurrence as much as the mechanical performances of some layers. The FEM analysis have been complemented by the experimental study of the mechanical behavior of the coating layer under the effect of rainwater, in order to better understand ETICS behavior over their service life.
\end{abstract}

Keywords: External Thermal Insulation Composite Systems (ETCS), Finite Element Methods (FEM), Mechanical behavior, Durability.

\section{Introduction}

Climate change and the request for better assets' energy performances given by the European Union (Directive EU 2018/844) are forcing the construction sector towards passive or even active buildings, i.e. assets with a positive balance between energy production and consumption. According to the (European Construction Sector Observatory, 2019) of the residential building stock in the EU Member States, on average 45.4\% of the buildings were built before 1969 and $75.4 \%$ before 1990 . This means that, not only designing and constructing energy efficient buildings should be targeted, but also retrofitting the building with energy efficient strategies to improve buildings performance through its lifespan should be considered (Sözer, 2019).

Building insulations play a crucial role in reducing energy demand. One of the most used technology to insulate new and refurbished buildings are the External Thermal Insulation Composite Systems (ETICS). According to (ETAG 004) an ETICS is "a system that comprises 
a prefabricated insulation product bonded onto the wall, or mechanically fixed using anchors, profiles, special pieces, etc..., or a combination of adhesive and mechanical fixings. The insulation product is faced with a rendering consisting of one or more layers (site applied), one of which contains a reinforcement. The rendering is applied directly to the insulating panels, without any air gap or disconnecting layer".

ETICS, have often been used in Europe since the 1970s, both in new buildings and in retrofitting. The popularity of this technology grew due to its advantages regarding other techniques of insulation. ETICS guarantees the reduction of the thermal bridges and greater thermal comfort due to the preservation of interior thermal inertia, providing a finished appearance similar to the traditional rendering (Tavares, 2020).

The increasing and progressive use of ETICS has also resulted in a significant number of failure cases. Among these, the main defects found in literature can be classified into four main types (Tavares, 2020):

\section{staining/color or texture changes; \\ joint defects; \\ loss of continuity/integrity defects; \\ loss of adhesion defects.}

Examples of loss of continuity/integrity are oriented or mapped cracks and defects in corners that are usually caused by a combination of different causes. Cracks in ETICS are not only a serious aesthetic defect, they are also a weak point for the entry of rainwater into the facade. The consequences of the exces sive preserce of water inside an ETICS system are its accelerated
degradation and a decty in the thermal resistande of the insulating layer. The latter compromides
the performance of the entire system.
Thus, a study on the development of cracks in ETICS coatings is of utmost inportance and
understanding the causes may allow for better designed and longer life façades.

for Stree at hithes s/www.scipedia.com to download the version without the watermark A research on the most common databases of scientific publications reveals how ETICS have been studied in relation to some of their characteristics and other performance of the building.

For example, Figure 1 shows a diagram obtained by searching SCOPUS and WebOfScience for the following research string: (ETICS OR "external thermal insulation composite systems") AND ("service life" OR durability OR (FEM OR "finite element method") OR crack* or "mechanical behavior"). This search string allows you to find articles that deal with ETICS and durability or service life, or ETICS and mechanical behavior, with attention to the occurrence of cracks.

It can be noted in Figure 1 (the biggest circle in picture) that ETICS have often been studied in relation to the thermal insulation requirement, which was easily foreseeable. For what is most relevant to the scope of this research, durability aspects of ETICS have been analyzed mainly in relation to moisture and, similarly, the keyword "degradation" has been often searched combined to "mold growth" and "biodegradation" especially on "housing". Nevertheless, some studies on cracks on ETICS can be found.

Durability of ETICS has been often associated to degradation of their coating layer due to mold growth (Kučeriková 2014, Stanaszek-Tomal, 2017). Although, ETICS generally perform satisfactorily if thoroughly designed and carefully erected, they are not very robust. Even minor 
errors in design techniques and/or craftsmanship can lead to rendering defects (Kvande, 2018).

(Tavares, 2020) after a survey of 378 façade found that stains or aesthetic changes are the most common anomalies and were identified in practically all claddings. In contrast, anomalies associated with loss of adhesion were only identified in $10.5 \%$ of the sample set.

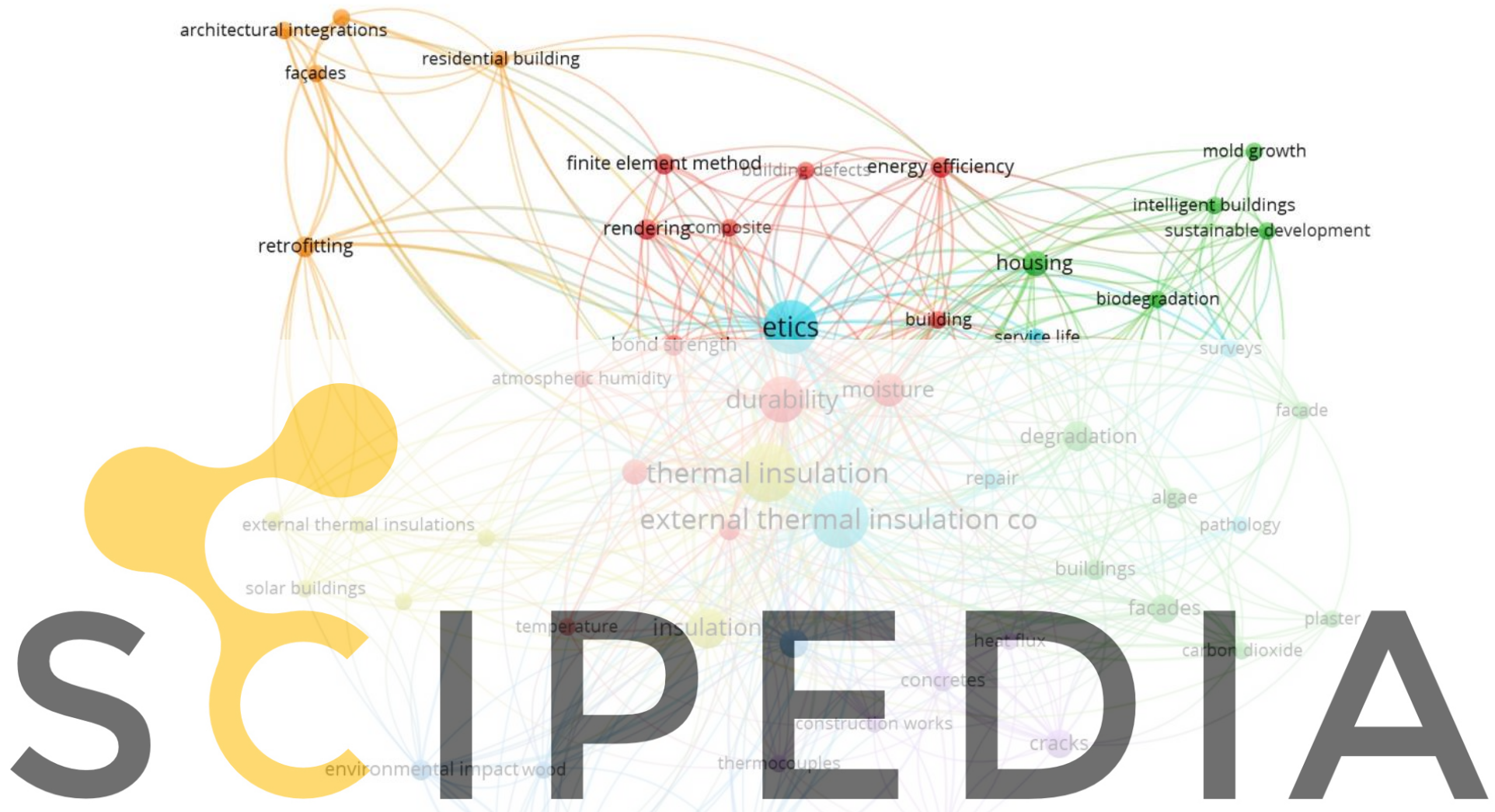

Register for free at https//www.scipedia.com to download the version without the watermark

life cycie assessment (ica)

Figure 1. Network analysis of the keywords ETICS, external thermal insulation composite systems, service life, durability, FEM, finite element method, cracks, mechanical behavior.

In a survey of the facade defects with ETICS in a cold climate made by visual inspection (Liisma, 2016) found that most of the ETICS defects were material rupture $(51 \%)$ and color/aesthetic defects $(40 \%)$. Only a small proportion of defects were associated with flatness $(9 \%)$.

\section{Methods and Tools}

The research is divided mainly into two great stages as pictured in Figure 2. The first one is dedicated to data gathering on both aging agents and materials' mechanical properties and to some pre-analysis needed to understand the behavior of the coating layer of ETICS. The second one is the actual FEM analysis and data post-processing for visualization.

Focusing on the first stage, an investigation of cracks in ETICS, conducted through 
interviews with experts and some analyses of failure cases, has shown that temperature variations are one of the major stressing agents in this type of degradation. Noteworthy, researches (Künzel, 1999) prove that during the course of the day the surface of ETICS is exposed to thermal and hygric variations of up to $40 \mathrm{~K}$ and $80 \% \mathrm{RH}$.

Accordingly, the climate of some locations was analyzed in order to define the stress conditions to which the ETICS coat was subjected. In particular, when choosing the locations to be analyzed, attention was paid not only to the maximum air temperature but also to seasonal and day/night temperature variations. Eventually, the choice of locations was also influenced by the spread of ETICS on the market. Once the locations have been selected thermal stresses on ETICS have been computed using the model WUFI® (Künzel, 1994), which has been developed at Fraunhofer-IBP in Germany since mid of the 1990ies. In this model the relevant heat and moisture transport processes within hygroscopic porous media are described by two partial differential equations which are solved by the help of a finite volume procedure.

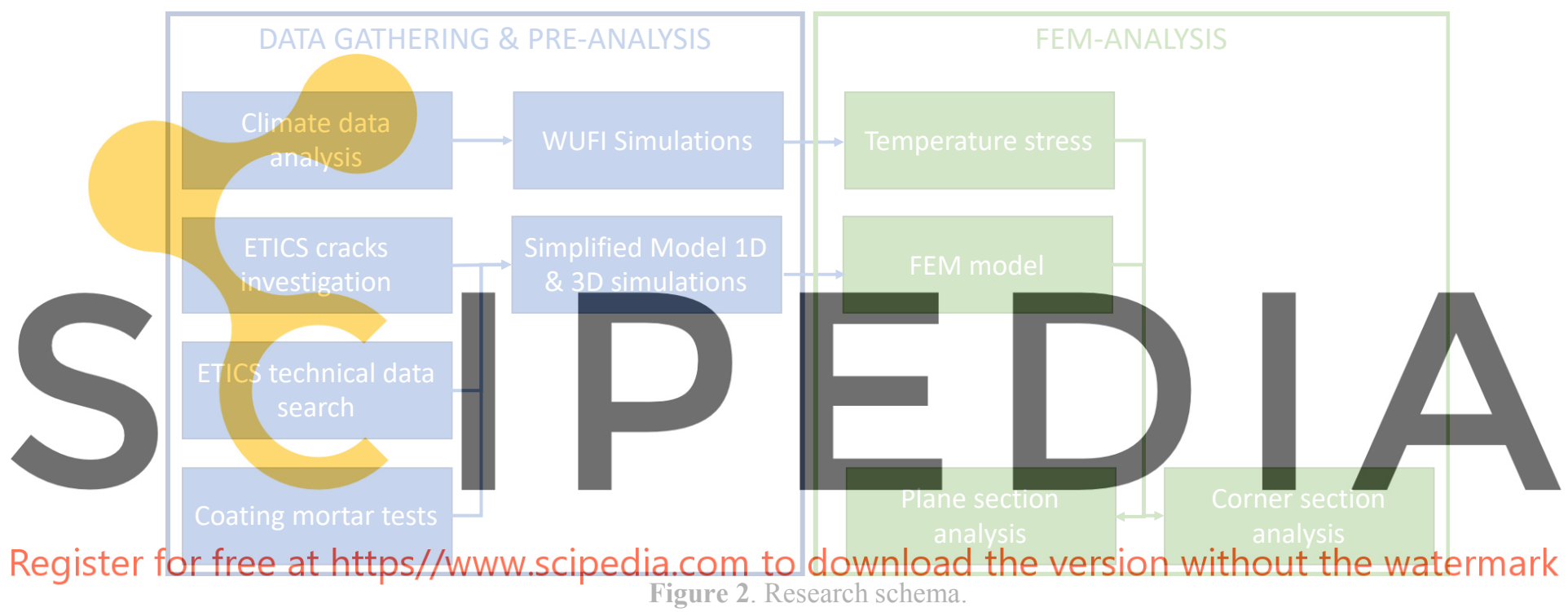

Alongside to the analysis of climate agents, simplified structural models have been created to better understand the phenomenon of the development of cracks on the external surface of ETICS. For example, a model was built by modelling the ETICS finishing layer as an elastic beam resting on a bed of springs whose rigidity is proportional to the compressive strength of the thermal insulation layer. These first analyses on simplified models have highlighted fundamental aspects for the prosecution of the research. It has emerged, for example, that in without imperfections in the installation phase or defects in the material such as the different thickness of the panels, the only thermal variations are not able to generate tension or compression stresses inside the coat that can cause the formation of cracks.

In the second stage of the research a nonlinear finite element model has been set-up for the mechanical analyses of ETICS. The model consists of seven insulating panels arranged in three rows so as to represent, considering the appropriate symmetries, the planar and central surface of the facade of a building. The chosen finite elements are of isoparametric kind, threedimensional, with 8 nodes and incompatible shape modes. The total number of finite elements is about 70000, with about 75000 nodes. 
On the ETICS bottom, i.e. where the system adheres to the supporting wall, fixed boundary conditions are imposed on surface parts physically glued. Boundary conditions, consistent with a periodic repetition of insulations panels, are set to the lateral surface.

FEM input is represented by the temperature distribution, along the ETICS thickness, computed by "WUFI" software in the first stage of the research. Non-linear kinematics has been adopted to perform the analyses.

Defects that may occur during the installation of the ETICS or imperfection in the thickness of the panels are modelled by a thickness reduction of the central panel. The onset of the fracture is checked by a Rankine criterion in the plaster.

In order to complete the finite element analysis and also to investigate particular configurations of the panels, different types of edge constraints have been imposed. The first stage of the research showed that in many cases the corners (edges of the facade, corners of doors and windows, corners in correspondence of balconies and loggias, ...) are places of frequent development of cracks. Thus, a second finite element model has been created to allow the analysis of these troublesome point in an ETICS façade.

Eventually, results FEM analyses were combined with some experimental investigation on the tensile strength of the coating made in the first stage of the research.

\section{Results}

The main research results are set out in this section. It should be noted that for all finite element models a double analysis has been made, one in the case of a polystyrene foam (EPS) insulation panel and another with

The 1D preliminary of cracks (due to instab stress is $\sigma_{c r}=6.1 \mathrm{MPa}$ the base coat is already cracked the same variabl
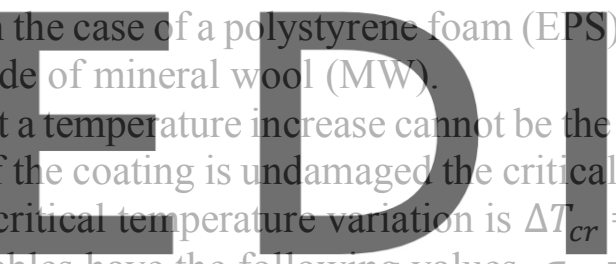
fllowing values, $\sigma_{c r}$ insulation
only cause
$=576 \mathrm{~K}$.If
$=3 . \mathrm{MPa}$

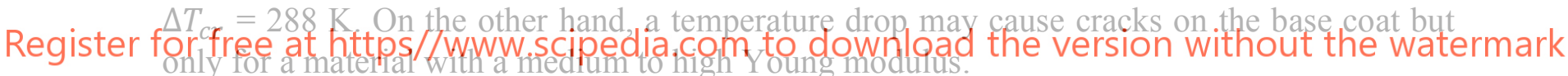

These preliminary results were confirmed by the 3D FEM analyses where a model made of seven insulation panel has been investigated using temperature distribution obtained from HMT analyses using weather data of the city of Milano. Even in FEM analyses, if the model has no imperfections, i.e. there are no errors in construction or insulation panels have no thick tolerances, then there are no signs of possible cracks. Otherwise, if errors or imperfection are modeled with one insulation panel (the central one in this case study) having a different thickness ( $1 \mathrm{~mm}$ thicker in this case study) then displacements are much bigger, as shown in Figure 3. Accordingly, in the coat significant stress concentrations at the joints of flanked insulation panels were found.

Figure 4 shows a comparison between stresses in the $\mathrm{z}$ direction, i.e. parallel to the longest side of the insulation panel, caused by a negative temperature variation may on ETICS made with two different materials for insulation layer: MS (a) and EPS (b). 


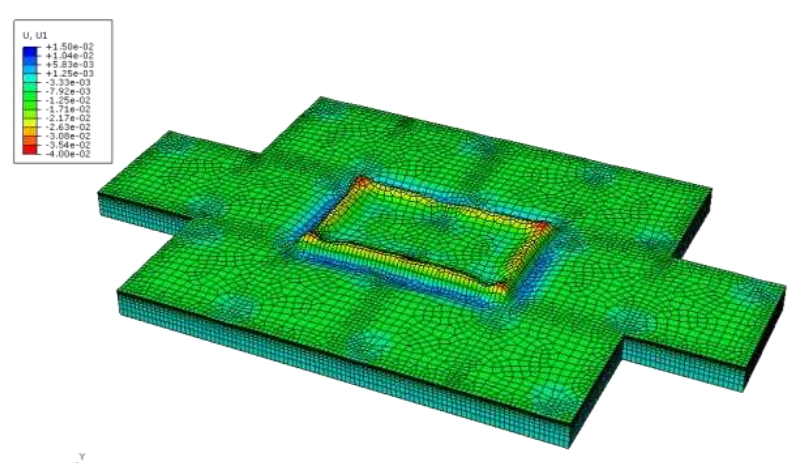

F.

Figure 3. FEM Analysis results for the plane section of the MW ETICS. Displacements in $x$ direction (thickness) $[\mathrm{mm}]$ for a positive temperature variation.

In both cases stresses in the coating layer were below the strength of the material. FEM analyses confirmed what had been found in the scientific literature and in the investigated fault cases: cracks on the coat of ETICS will develop if a) the external face of the insulation panels does not belong to a perfect plane; b) the coat has a high Young (elastic) modulus and c) there are high temperature variations.

a)
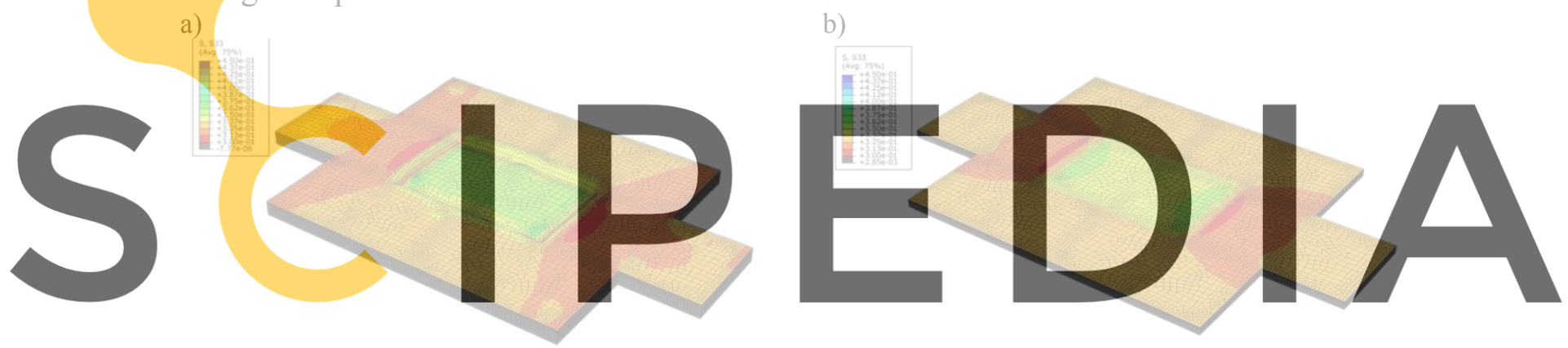

Register for free at https//www.scipedia.com to download the version without the watermark

Figure 4. Comparison between mineral wool (a) and EPS (b). Stresses z direction [MPa] for a negative temperature variation.

In order to simulate the behavior of an ETICS near a corner some FEM analyses on a single insulation panel with two unconstrained edges have been done. An example of the results of these analyses is shown in Figure 5. The difference in the thermal expansion coefficient between the two insulation panel materials led to a huge difference in stresses in the coat layer, namely in the ETICS made of EPS stresses inside the coat are up to 6 times the stresses in ETICS made of mineral wool and with the given thermal stresses (city of Milano, medium dark color coat) are dangerously close to the strength of the coat.

Since the tensile strength of the coating play a crucial role in the development of cracks, 12 coat samples were tested to measure their tensile strength. Six of them were characterized by a high water content (immersed) and 6 with a standard water content (dry). 
a)

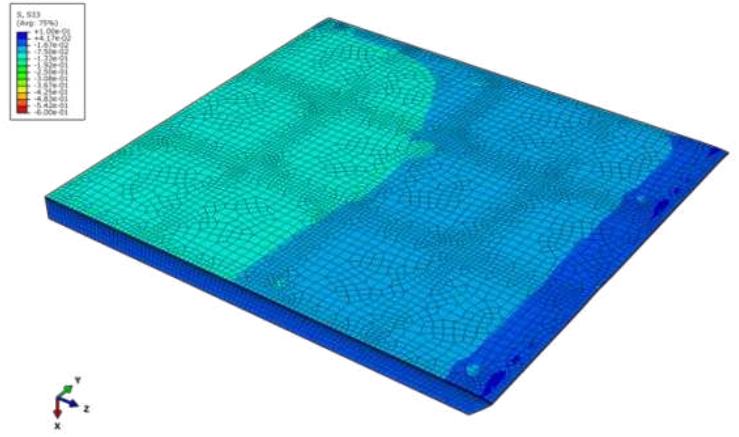

b)

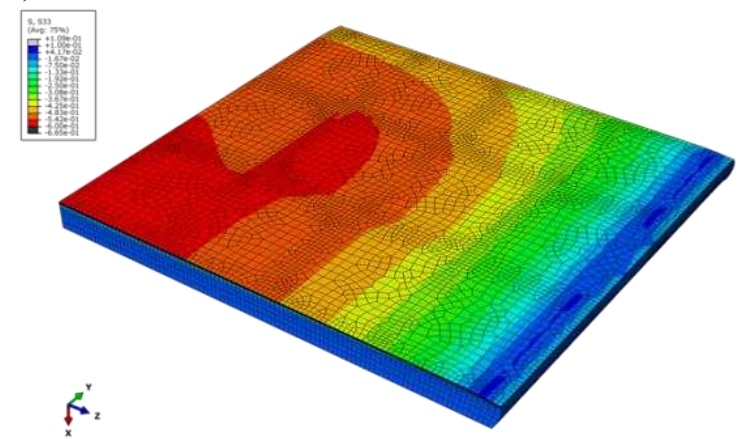

Figure 5. Comparison between mineral wool (a) and EPS (b). Stresses [MPa] when two edges of ETICS are unconstrained.

Experimental results proved that the average tensile strength applied to obtain a $2 \%$ strain varies significantly comparing the dry samples and the immersed ones with an average $42 \%$ reduction. By combining the results obtained in the two phases of the research, we can say that high water contents can easily halve the critical thermal variation, i.e. the thermal variation causing cracks on the ETICS coat. This high reduction is all the more dangerous as the elastic modulus of the insulating material increases.

\section{Discussions and Conclusions}

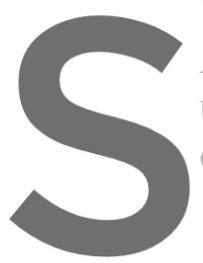

After a deep literature review performed to find
used in FEM simulation and some preliminary si
of the phenomena, two different kind of models
$\quad$ - one where ETICS is fully constrained to any singularity such as windows, doors
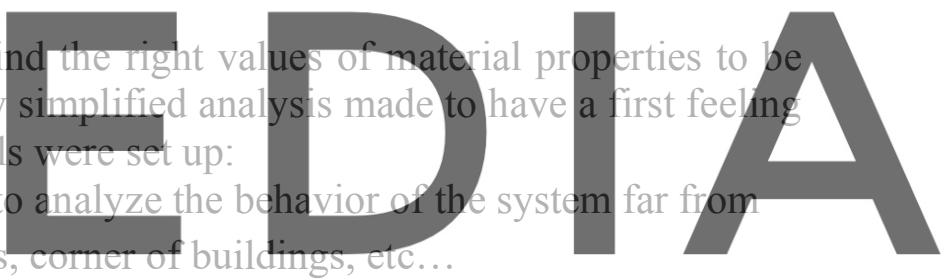

one where two side of the ETIC are unconstrained in order to investigate what

Register for free at https/swww. scipedia, com to downlgad the versjon without the watermark

In both cases thermal stresses were computed starting from a temperature distribution given by HMT simulations.

FEM simulations using the fully constrained model showed that cracks in the coat layer are mainly a consequences of steps in two near panels (a small step from one panel to the near one may be due even to a small tolerance in the thickness of the panel or to defects in the support layer and it's always present) and that a coat with high Young modulus suffers more than a rigid one high temperature variations. Simulations made with the unconstrained model highlighted that thermal expansion coefficient of the insulation panels and its compressive strength in the direction perpendicular to the main face are important factors for cracks development. An insulation panel with a low thermal expansion coefficient behave better in hot climate, the case studies showed, for example, that ETICS made with mineral wood insulation have stresses in the coat layer six times lower than the ones made with EPS. Some design principles can be deduced from FEM simulations:

- (if possible) always try to limit the thermal excursion of the coat layer of the ETICS using light colors in hot climate (or where there is a high sun radiation); 
- use insulation panels with low tolerance in the thickness (small manufacturing errors) and fix them on a plaster layer (or be sure to have a very flat surface);

- in hot climate (or where there is a high sun radiation) use insulation panels with a low thermal expansion coefficient and a high compression resistance (in the direction perpendicular to the main surface);

- it is always better to protect ETICS from rainwater because the tensile strength of the coat decreases significantly in presence of water, thus lowering the threshold (temperature variation) of cracks.

\section{Acknowledgements}

The authors would like to acknowledge and thank PhD Riccardo Paolini for his invaluable contribution to this research. This research was partially founded by Rockwool International A/S, to which the authors express their deepest gratitude.
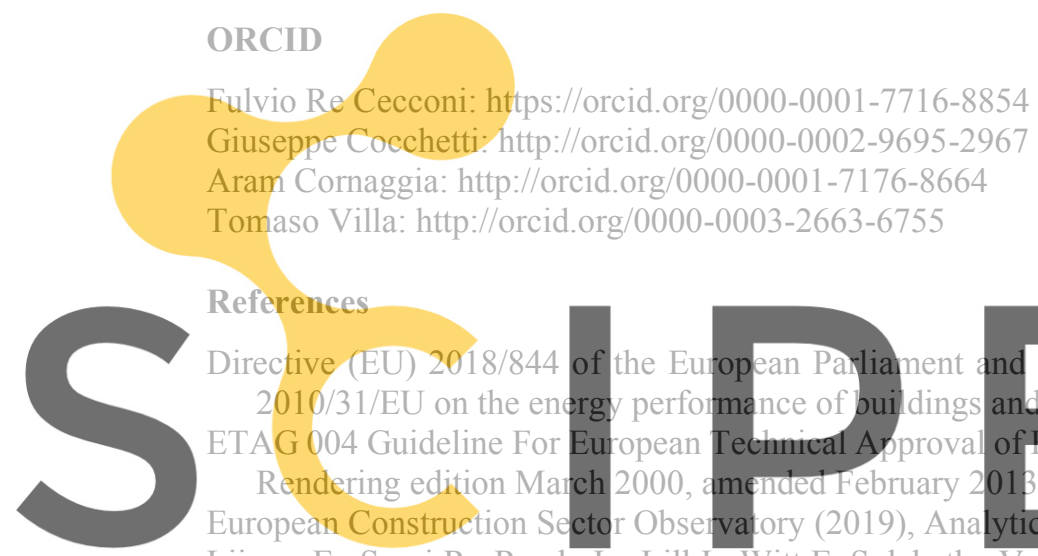

References

Directive (EU) 2018/844 2010/31/EU on the encrgent

ETAG 004 Guideline For

European Construction Sect

Liisma E., Sepri R., Raado I.
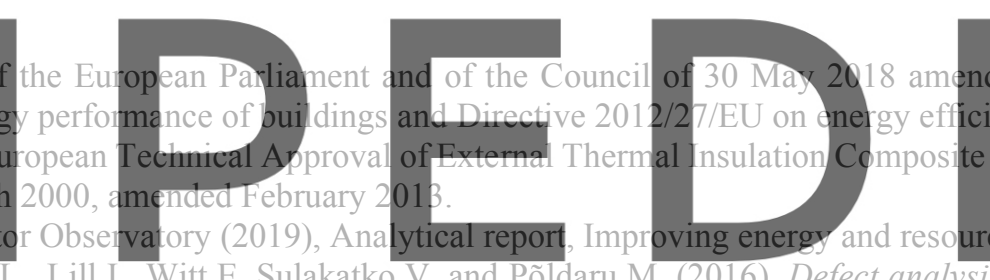
fcade walls with ETICS solutions in cold climate conditions, Central Europe towards Sustainable Building

Register for (frees at), httas//Wwww.scipedia.com to download the version without the watermark

Kučeriková V., Kraus M. and Kubečková D. (2014). Analysis of the Degradation of External Plasters in the Buildings with ETICS, Advanced Materials Research, Vol. 1041, Pages 15-18, https://doi.org/10.4028/www.scientific.net/AMR.1041.15

Künzel, H.M. and Holm, A. (1999). Praktische Beurteilung von Putzen durch moderne bauphysikalische Bewertung. WTA-Schriftenreihe, Vol. 20, S.177-132.

Künzel, H.M. (1994). Verfahren zur ein- und zweidimensionalen Berechnung des gekoppelten Wärme- und Feuchtetransports in Bauteilen mit einfachen Kennwerten. Dissertation Universität Stuttgart

Kvande, T., Bakken, N., Bergheim, E., and Thue, J.V. (2018). Durability of ETICS with Rendering in Norway Experimental and Field Investigations. Buildings, Vol. 8, 93, https://doi.org/10.3390/buildings8070093

Stanaszek-Tomal E. (2017). The Problem of Biological Destruction of Façades of Insulated Buildings - Causes and Effects, IOP Conf. Ser.: Mater. Sci. Eng. 245 032012, https://doi.org/10.1088/1757-899X/245/3/032012

Sözer H., Sözen H. (2019) Energy saving, global warming and waste recovery potential of retrofitting process for a district, Journal of Cleaner Production, Volume 238, ISSN 0959-6526.

Sulakatko, V., and Lill, I. (2019). The economic relevance of on-site construction activities with the External Thermal Insulation Composite System (ETICS). International Journal of Strategic Property Management, 23(4), 213-226. https://doi.org/10.3846/ijspm.2019.7071

Tavares J., Silva A. and de Brito J. (2020). Computational models applied to the service life prediction of External Thermal Insulation Composite Systems (ETICS), Journal of Building Engineering, Volume 27, ISSN 23527102, https://doi.org/10.1016/j.jobe.2019.100944. 